\title{
ENTRE IDENTIDADES E MICRORRESISTÊNCIAS: ONDE ESTÃO AS LÉSBICAS?
}

\author{
Maiquel Ângelo Dezordi Wermuth ${ }^{1}$ \\ Pamela Canciani ${ }^{2}$
}

\section{Resumo}

A relação com o corpo excede o domínio do particular, já que os sujeitos estão inseridos em contextos socioculturais, transitando em direção ao público, e assumem suas individuações a partir do contato com os outros. Dessa forma, para que haja visibilidade da existência lésbica, verifica-se a necessidade de superação, primeiramente, de padróes imputados pelo sistema patriarcal e, em um segundo momento, de um apagamento social sofrido pelas mulheres lésbicas no decorrer da história. Essa pesquisa se justifica pela urgência de rompimento de estereótipos e estigmas que permeiam a identidade lésbica: ao se (re)conhecer a diferença no meio acadêmico, também é possível vislumbrar uma mudança cultural e social, depois de ultrapassada a invisibilidade imposta a essas mulheres. O método de pesquisa a ser utilizado será o hipotético-dedutivo. A técnica empregada será a pesquisa bibliográfica, a partir de consultas em livros, artigos científicos, revistas, legislações e demais documentos pertinentes.

Palavras-chave: Lésbicas; Identidade; Microrresistência; Direitos Humanos.

\section{INTRODUÇÃO}

Em uma sociedade formada por categorias de gênero, a sexualidade subversiva tende a ser marginalizada ou invisibilizada. O sistema de dominação patriarcal, que este enredado nas relações sociais e determina padrões, anula a existência de identidades não reconhecidas pelos seus códigos. O testemunho de uma memória que não é dado pelas suas protagonistas, torna impossível estabelecer uma identidade de corpos políticos individuais enquanto eles não se manifestam coletivamente. Assim, este artigo parte do seguinte problema de pesquisa: como as diferenciações sexuais pautadas em um sistema majoritário heterossexual-patriarcal contribuíram para a invisibilidade e a anulação de direitos das mulheres lésbicas?

A identidade, além de identificação coletiva e de pertencimento, proporciona uma ansiedade individual de se (re)conhecer. No caso das mulheres lésbicas, o apagamento social e o pouco espaço oferecido para a construção de características suficientes para uma identificação impedem a formação de uma identidade que seja,

\footnotetext{
${ }^{1}$ Doutor em Direito Público pela UNISINOS. Professor do Mestrado em Direitos Humanos da UNIJUÍ. Professor dos Cursos de Graduação em Direito da UNIJUÍ e UNISINOS. E-mail: madwermuth@gmail.com

${ }^{2}$ Mestranda em Direitos Humanos pela Universidade Regional do Noroeste do Estado do Rio Grande do Sul - UNIJUÍ. E-mail: madwermuth@gmail.com
} 
de fato, inerente ao sujeito lésbica. Por outro lado, questiona-se: é possível construir uma identidade fundamentada em aspectos relacionados à sexualidade? Em práticas? O elo central de identificação dessas mulheres é a prática sexual homoerótica ou algo que vai além disso? É o que se faz necessário perquirir, já que as transformações sociais e os discursos dominantes, norteados por significações distorcidas, patológicas ou estereotipadas, debelaram o espaço que seria de construção social de uma identidade lésbica.

Uma vez evidente o fenômeno da (in)visibilidade lésbica, é necessária uma investigação da identidade como mecanismo de microrresistência e busca de direitos. Ainda, não se pode olvidar que, no caso de seres tão plurais como as mulheres, uma identidade será um ponto de convergência imutável, e uma pesquisa acadêmica nunca poderá dar conta da verdadeira realidade perscrutada no âmbito social. Carece, então, investigar o que antes foi dito sobre a identidade em si e, em seguida, atrelar conceitos - e significados - à realidade do corpo político das lésbicas.

A opressão e a repressão, bem como a (in)visibilidade desses corpos políticos, produzem violências dirigidas às mulheres lésbicas. Assim, a existência de uma identidade do corpo lésbico na cena política atua como mecanismo de microrresistência. Examinar como as transformações sociais e o empoderamento das mulheres, por meio de lutas sociais, contribuíram para a afirmação dos direitos de gênero é prerrogativa inicial para verificar se essas mudanças cumprem as necessidades das mulheres lésbicas; além disso, é possível analisar como a identidade pode se transformar em um mecanismo de defesa e busca do "direito a ter direitos".

Pesquisar o tema em tela se justifica pela urgência de se reconhecer direitos e garantias a uma minoria "duplamente" vulnerável no seio social. Com efeito, as mulheres lésbicas são sujeitos sociais incluídos politicamente no movimento feminista e no movimento LGBT. Por outro lado, identifica-se a roupagem específica que tomam as violências sociais direcionadas às lésbicas. Não se trata apenas de silenciamento e apagamento social, mas também, quando rompida essa barreira, diz respeito à opressão de gênero difundida pelo patriarcado e ao preconceito quanto à orientação afetiva-sexual, por meio do assédio, da violência física e psicológica, da violência institucional e simbólica, e, por fim, da violência sexual.

Assim, é possível verificar como o modo de viver das lésbicas exerce influência sobre uma ordem social estruturada e voltada para uma lógica de dominação masculina. A sexualidade é vista como reprodutora de práticas que atuam no imaginário, o que forma o discurso. Essa prática foi denominada por Foucault (1979, p. 244) como o dispositivo da sexualidade: "um heterogêneo que engloba discursos, instituições, organizações arquitetônicas, decisões reguladoras, leis, medidas administrativas, enunciados científicos, proposições filosóficas, morais, filantrópicas", e que, ainda de acordo com a acepção do filósofo francês, "funciona segundo técnicas móveis, polimorfas e conjunturais de poder [...] como razão de ser, não o reproduzir, mas o proliferar, inovar, anexar, inventar, penetrar nos corpos de maneira cada vez mais detalhada e controlar as populações de modo cada 
vez mais global." (FOUCAULT, 1988, p. 102).

Este artigo está dividido em três seções. No primeiro tópico, abordam-se a discussão do rapto da identidade da mulher lésbica, bem como os meios necessários para o (re)conhecimento de uma identidade. Em seguida, serão apresentadas considerações sobre a identidade lésbica no imaginário social do Ocidente e como ele é construído. Por fim, a análise diz respeito à questão de como se edifica uma microrresistência no cenário brasileiro e se a identidade da mulher lésbica pode ser percebida como mecanismo de reconhecimento.

\section{O DESAFIO IDENTITÁRIO DA LÉSBICA}

O desafio da mulher lésbica consiste em ser identificada em um mundo já pautado pelo imaginário masculino. Diante de toda a esquizofrenia em torno do "ser" lésbica que perpassa os estigmas já demonstrados na introdução, perde-se a construção real do que isso significa. Kate Millet (1970), visionária escritora feminista, demonstra em seu livro Política Sexuala dificuldade de se formarem novos discursos, já que na totalidade de uma política sexual as mudanças genuinamente revolucionárias deveriam ter uma influência maior à escala política sobre os papéis sociais entre os sexos.

A explicação dada por ela é que, por conta da manutenção do patriarcado como um determinante universal, não se esperava que o assunto fosse posto em tela. Porém, como a autora previu, houve uma modificação na organização da sociedade, com significativas transformações na libertação das mulheres. No entanto, o patriarcado segue estruturando as relações sociais em categorias binárias. E é justamente por não haver outras definições para as categorias homem/mulher e dispositivos de significação masculino/feminino que esta pesquisa segue usando essa terminologia. Millet (1970, p. 10), além de denunciar esse cenário, vai além e afirma que:

uma revolução sexual exigiria antes de mais, talvez, o fim das inibições e tabus sexuais, especialmente aqueles que mais ameaçam o casamento monógamo tradicional: a homossexualidade, a ilegitimidade, as relações sexuais pré-matrimoniais e na adolescência [...] Em primeiro lugar, uma revolução sexual acabaria com a instituição patriarcal, abolindo tanto a ideologia da supremacia do macho como a tradição que a perpetua através do papel, condição e temperamento atribuídos a cada um dos dois sexos. Isto permitiria uma integração de subculturas sexuais, uma assimilação de ambos os lados da experiência humana até aqui excluídos da sociedade. Da mesma forma, seria conveniente reexaminar as características definidas como masculinas ou femininas e reconsiderar o seu valor no aspecto humano.

Não é à toa que Shulamith Firestone (1976) articulou em seu livro $A$ dialética do Sexo conjecturas que corroboram o pensamento de Kate Millet (1970), para quem as cristalizações dos papéis sociais instituídos em categorias estão tão enraizadas que se tornaram invisíveis. A tese dessas duas autoras faz sentido ao notar o "beco sem saída” no qual a busca da identidade se encontra, havendo somente uma lógica política já formada no imaginário social que norteia as representações. Essas acepções são colocadas aqui para demonstrar o ímpeto 
deste estudo: a plena libertação sexual das mulheres, que beneficiaria, sobretudo, as lésbicas. Faz-se ecoar, assim, a fala de Shulamith Firestone (1976, p. 11): "se houvesse outro termo mais abrangente do que revolução, nós o usaríamos".

Enquanto não se concretizam a completa revolução sexual e a total libertação das mulheres das amarras sociais, buscam-se meios para isso. A identidade é aqui colocada como um instrumento de microrresistência, pois somente seres visíveis podem encabeçar demandas, já que, sem um lugar que demonstre a opressão e a violência vividas (nesse caso, o que constitui a "lesbofobia"), o direito não consegue chegar aos sujeitos que dele dependem.

Conforme explica Bauman (2005), as pessoas em busca de identidade se veem, invariavelmente, diante da tarefa intimidadora de "alcançar o impossível". Essa expressão genérica implica, como se sabe, tarefas que não podem ser realizadas no "tempo real", mas que serão presumivelmente realizadas na plenitude do tempo - na infinitude. Os corpos políticos das lésbicas são sujeitos de representação, que se constitui com articulação política. Porém, sabe-se que não será algo imediato, mas algo que já foi começado.

Para ilustrar, "não somos mulheres gays" é a frase que inicia o artigo de Gláucia Almeida e Maria Luiza Heilborn (2008). Essa proposição foi adaptada de um postal do grupo Nuances, uma organização não governamental (ONG) gaúcha fundada em 1991, e demonstra a afirmação de uma identidade lésbica, por meio de sua progressiva autonomização, em relação a outras identidades políticas. Segundo as autoras, esse processo afirmativo foi iniciado na década de 1970 e intensificado a partir dos anos 1990, com o crescimento das ONGs lésbicas.

Para Bauman (2005), existem identidades ligadas a comunidades de dois tipos: a comunidade de vida e de destino. A última refere-se à existência em razão das ideias que unem as entidades que participam dela, ou seja, a comunidade fundida por ideias que fazem parte de um mundo de diversidades e policulturas. Por conta dessas ideias, em torno das quais se desenvolvem essas "comunidades de indivíduos que acreditam", Bauman (2005, p. 17) explica a necessidade de comparar, reconsiderar, fazer escolhas já feitas em outras ocasiões e tentar conciliar as demandas contraditórias e frequentemente incompatíveis.

Por isso, o movimento das mulheres lésbicas apresenta-se de forma autônoma ao movimento LGBT em geral e, até mesmo, em relação ao movimento feminista. Contudo, isso não representa de modo algum um intuito de sectarizar, mas apenas uma necessidade de concentrar demandas próprias:

A partir da segunda metade dos anos 1990, houve um adensamento da teia de sustentação de grupos exclusivamente formados por lésbicas, o fortalecimento da participação lésbica nos grupos mistos, o surgimento de novos grupos (especialmente ONGs) e de novas lideranças. Ocorreu também uma mudança na relação entre estes grupos e o Estado brasileiro, bem como com outros movimentos sociais organizados, como o homossexual, o feminista, o feminismo negro e o negro. Apesar da autonomização do movimento diante das demais organizações homossexuais, há ainda uma agenda comum. Demandas, ideologias, valores e tradições são semelhantes aos do movimento gay. No entanto, há repertórios cada 
vez mais autônomos, assim como um princípio articulatório interno mais independente, em função, principalmente, da entrada em cena das ONGs a partir da década de 1980, quase em substituição total aos grupos informais (ALMEIDA; HEILBORN, 2008, p. 227).

A identidade aparece como "um monte de de problemas", e não uma campanha de tema único. Para Bauman (2005, p. 18), na era da sociedade "líquido-moderna”, na qual o mundo está repartido em fragmentos mal coordenados e as existências individuais estão fatiadas numa sucessão de episódios fragilmente conectados, sempre há alguma coisa a explicar, desculpar, esconder, ou, pelo contrário, corajosamente ostentar, negociar, oferecer e barganhar.

Há diferenças a serem atenuadas, desculpadas ou ressaltadas e esclarecidas. O referido autor aponta as identidades como flutuantes no ar; algumas de escolha própria, outras infladas e lançadas por outras pessoas. Além disso, alerta para a necessidade de defesa da primeira em relação à segunda, por conta da probabilidade de desentendimento. "Pode-se começar até a sentir-se chez soi (em casa), em qualquer lugar, mas o preço a ser pago é a aceitação de que em lugar algum se vai estar total e plenamente em casa." (BAUMAN, 2005, p. 20).

Dessa forma, é possível entender as limitações para a concepção de corpo político das lésbicas. As representações que norteiam esse corpo acrescentam sentidos que limitam a sua insurgência a adjetivações desqualificadoras, pejorativas e estigmatizantes. Assim, como pensar, na contemporaneidade, nas categorias de visibilização que irrompem com esse padrão e permitem a microrresistência das mulheres lésbicas?

Antes de tudo, cabe entender como essa chamada "crise de identidade" - em que se observam o declínio das velhas identidades, o surgimento de novas identidades e a fragmentação do indivíduo moderno, visto até então como unificado - está abalando a estabilidade social. Logo, é preciso explorar a identidade cultural na modernidade tardia e verificar como essa crise se permuta na identidade lésbica.

A identidade cultural é aquela que se refere ao "pertencimento". A descentração do sujeito (ou deslocamento, "perda de si” estável) é colocada como cerne de preocupação por Hall (2001), pois a transformação das identidades modernas está também mudando as identidades pessoais, abalando a ideia que se aplica sobre os homens como sujeitos integrados. Quando a identidade é colocada em crise, questiona-se se a própria modernidade não está passando por um processo de transformação. $O$ autor ainda verifica se a humanidade também se tornou "pós" (HALL, 2001). ${ }^{3}$

Identificar-se com” significa dar abrigo a um destino desconhecido, que não pode ser influenciado ou controlado. Conforme Bauman (2005, p. 36-37), a identidade encontrava pertencimento tradicionalmente na

\footnotetext{
${ }^{3}$ Hall (2001) passa a exemplificar as questões políticas da fragmentação (pluralização) das identidades: as transformações sociais polarizam o mundo em diferentes classes, religiões, etnias, entre outras, o que traz consequências políticas, já que as identidades são contraditórias e se cruzam e se deslocam. Não se podem alinhar identidades diferentes para criar uma "identidade mestra", assim a paisagem política do mundo moderno é fraturada por identificações rivais. Uma vez que a identidade muda de acordo com a forma como o sujeito é interpelado, a identificação não é automática, mas pode ser ganhada ou perdida. "Ela tornou-se polarizada, esse processo é, às vezes, descrito como constituindo uma mudança de uma política de identidade para uma política de diferença
} 
família, no trabalho, na vizinhança, etc, espaços que se tornam agora indignos de confiança ou estão indisponíveis. Daí a crescente demanda pelo que ele chama de "comunidades guarda-roupa", assim invocadas em razão de aparentemente "pendurarem" problemas individuais. Elas são provocadas por qualquer evento espetacular ou escandaloso, como um novo inimigo público, um crime, uma partida de futebol, etc. Essas comunidades permanecem reunidas enquanto dura o espetáculo; logo, são de curta duração e diferem da sonhada comunidade calorosa e solidária. Assim, a identidade particular tende a ser trocada por uma "rede de conexões".

O processo de mudança conhecido como globalização exerce impacto sobre a identidade cultural. As sociedades modernas são sociedades de mudanças constantes, rápidas e permanentes. Nas sociedades conservadoras, a tradição é um meio de lidar com o tempo e o espaço; já na modernidade, em contraste, as práticas sociais são constantemente examinadas e reformadas à luz das informações recebidas sobre aquelas próprias práticas (GIDDENS, 1990).

\section{A DIFÍCIL EXISTÊNCIA LÉSBICA NO IMAGINÁRIO SOCIAL OCIDENTAL}

A aceleração de processos globais, de forma que se percebem os espaços menores e as distâncias mais curtas, permite que os eventos em determinado lugar apresentem influência imediata sobre distintas pessoas e lugares longínquos. $\mathrm{O}$ impacto da globalização sobre a identidade está associado ao conceito de que o tempo e o espaço são coordenadas básicas para a representação, ou seja, todo meio de comunicação (escrita, pintura, desenho, fotografia) deve traduzir o seu objeto em dimensões espaciais e temporais. Assim, a moldagem e a remoldagem de relações no espaço-tempo, no interior de diferentes sistemas de representação, têm efeito profundo sobre a forma como as identidades são representadas e localizadas.

Isso posto, qual é o canal utilizado para representar as lésbicas? Como elas se apresentam no seio social? Estereotipadas? Sim, já restou demonstrado. Politicamente, podem ser caracterizadas como parte de um movimento autônomo que busca demandas a fim de dar conta da problemática da violência (aspectos sobre os quais se falou brevemente e que serão retomados para melhor explicar como foram organizados os movimentos de resistência lésbica no Brasil). Porém, ainda se encontra em aberto o que de fato constitui uma lésbica. Assim como Simone de Beauvoir (1949) questionou o que é uma mulher, indaga-se agora: o que é uma lésbica? O que se sabe provém de uma construção social produzida pelas relações de poder e discursos dominantes, da mesma forma que se constitui o imaginário social em torno do mito da mulher, desvendado também por Beauvoir e suas seguidoras.

O binário social masculino-feminino gera a problemática da falta de identificação da lésbica, já que a lesbianidade em si é uma categoria não reconhecida quando inserida nessa polarização; e, longe de criar verdades 
absolutas, essa pesquisa não busca um único caminho definidor de identidade, mas uma construção que desvele minimamente a realidade vivida pelas pessoas lésbicas.

O pensamento de Jacques Derrida referente à desconstrução é ponto crucial para o entendimento da identidade lésbica no seio da representação social binária em comento. A descoberta de Derrida acerca de que toda estrutura binária opositiva constrói a coluna sobre a qual a metafísica se erige, a partir de uma hierarquização conceitual que rejeita o singular, ou seja, um poder soberano universal - no qual, aqui, se pode situar o patriarcado como colonizador da produção de conhecimento científico sobre o gênero/mulher/feminino - é que o pensamento da desconstrução do autor designa como uma invasão teórica e prática, no anseio de fluir essas oposições, até o ponto de sua não pertinência (HERMES, 2013).

Ao se hierarquizar conhecimentos e, principalmente, torná-los opositivos, a fim de que apenas um dos elementos dessa dualidade tenha o domínio sobre o que é uma "verdade" socialmente conhecida, exclui-se a possibilidade de criação de outros elementos que possam a ser igualmente verdadeiros. Este é o ponto de convergência da pesquisa com o pensamento desconstrutivista de Derrida: não se encontra um ponto de pensamento "fora" da estrutura de conhecimento já construída no imaginário da "produção" do que é uma mulher lésbica, pois

o tipo de transgressão que faz justiça ao próprio movimento interno do pensamento, a desconstrução, só se dá no interior mesmo do pensamento, e não em um "fora", pois nunca se poderá habitar outro lugar senão o da linguagem, e é por essa razão que este tipo de transgressão implica somente o fato de o limite ou as margens do pensamento estarem sempre em movimento (HERMES, 2013, p. 229).

O principal argumento que norteia o desafio proposto segue a linha de pensamento de Tania Navarro Swain (2015, p. 188), historiadora que se debruça às questões do feminismo e, principalmente, aos aspectos relacionados com as mulheres lésbicas. No que diz respeito a essa identidade, a autora afirma que "nem o sexo biológico nem o gênero nem as práticas sexuais podem dar uma definição do ser humano, atestando uma essência qualquer ou uma substância estável de homogeneidade individual”, já que, inserida num meio social encharcado pela heterossexualidade compulsória, muitas vezes, casais de lésbicas reproduzem uma divisão generalizada de papéis sexuais, exemplo da dificuldade de situar um indivíduo fora do contexto em que ele se forma.

Ao analisar esse contexto pelo fenômeno da heterossexualidade compulsória, explicado por Adrienne Rich (2012), que demonstra como o apagamento social e as relações de gênero agem sobre as lésbicas como fio condutor que as levam de volta à sua natural inclinação de mãe, esposa, educadora e responsável pela prole, compreende-se que tudo isso só pode ser observado em uma relação com outro homem, visto que todas essas características são atribuídas ao binarismo de gênero. Rich (2012, p. 11) discorre sobre algumas formas específicas de controle:

Algumas das formas de o poder masculino se manifestar são mais facilmente reconhecidas do que outras, ao reforçar a heterossexualidade sobre as mulheres. No entanto, cada uma das 
que eu listei vem adicionar-se ao feixe de forças pelo qual as mulheres têm sido convencidas de que o casamento e a orientação sexual voltada aos homens são vistos como inevitáveis componentes de suas vidas - mesmo se opressivos e não satisfatórios. O cinto de castidade, o casamento infantil, o apagamento da existência lésbica (exceto quando vista como exótica ou perversa) na arte, na literatura e no cinema, e a idealização do amor romântico e do casamento heterossexual são algumas das formas óbvias de compulsão, as duas primeiras expressando força física, as duas outras expressando o controle da consciência feminina.

Monique Wittig e Adrienne Rich, autoras que não poderiam ser omitidas nesta pesquisa, aprofundam a análise em relação às lesbianidades, em primeiro lugar retirando-as do campo estreito das práticas sexuais, já que o relacionamento entre mulheres não se pauta somente em práticas homoeróticas. Elas também mostram até que ponto o que está em jogo tanto à lesbianidade quanto à heterossexualidade não se encontra no campo da sexualidade ou naquele do poder, retomando o conceito de biopoder cunhado por Foucault (1988). Para ambas, a heterossexualidade, além de ser uma aptidão sexual natural nos seres humanos, é imposta às mulheres pela força, quer dizer, ao mesmo tempo pela violência física e material, inclusive econômica, e por um sólido controle ideológico, simbólico e político, o qual faz intervir um conjunto de dispositivos que envolvem aspectos associados desde a pornografia até a psicanálise (FALQUET, 2012).

A partir disso, é possível entender o caráter subversivo e a resistência da mulher lésbica como um corpo político. "A identidade nômade é assim uma posição de sujeito ocupada em uma situação, em uma sociedade dada” (NAVARRO, 1999, p. 1.236); logo, as mulheres lésbicas assumem uma posição social em contraponto às ideologias de poder e dominação, tornando-se uma potência coletiva e individual. Embora sejam seres plurais, as práticas convergem formando um uno, no qual a vida política e as subjetividades aludidas partem dessa constituição, envolvendo teorização e compreensão dos discursos e memórias avaliadas a partir do mundo interno, que se relaciona com o mundo externo.

O temor de cair no essencialismo está presente quando se reivindica uma identidade, pois se liga o ser a uma prática, a uma atração, a um querer, que não é tão particular assim, mas ainda pertence a seres plurais. Incutir uma definição já é uma delimitação, é cercar um espaço que logo dará origem a novas exclusões sociais de seres que não se encontram nesse espaço. E pode-se reportar o quanto é essencial essa identidade inclusive para responder às exigências de uma moldura binária de pensamento que vem sendo criticada. Busca-se situar as mulheres lésbicas fora das estruturas que as aprisionam, como um ser subversivo que busca transformar o calabouço social em que se encontram.

Observando como atualmente se posicionam as mulheres lésbicas, é possível verificar o caráter subversivo de um ser que, ainda diante de tantas adversidades, resiste em ser quem é, e resiste, sobretudo, a uma estrutura que não lhe permite ser quem é. Ao se colocar a lésbica na conceituação de Giorgio Agamben (2010) 
sobre a vida nua ${ }^{4}$, pode-se verificar que ela se insere como um ser pertencente a uma zona de anomia de direitos, que, vivendo e resistindo em uma sociedade organizada nos moldes patriarcais, encontra-se em um "campo", que "é apenas o local onde se realizou a mais absoluta conditio inhumana que se tenha dado sobre a terra" (AGAMBEN, 2010, p. 162).

Agamben (2010) promove a visualização do campo não como local histórico, mas como um nomos do espaço político em que ainda se vive. Os campos não nascem do direito ordinário, mas do estado de exceção e da lei marcial. A base jurídica do internamento compulsório é a custódia protetiva dada livremente ao poder para ser utilizada contra indivíduos não dependentes de qualquer conduta penalmente relevante. Agamben procura analisar o campo não apenas como um fato histórico ou uma anomalia pertencente ao passado, mas como uma estrutura jurídica de como os fatos ocorreram ali e de como a matriz oculta, o nomos do ocorrido ali ainda permeia a política que se vive.

O campo é o espaço que se abre quando o estado de exceção se torna a regra; ele é um pedaço territorial colocado fora do ordenamento jurídico normal, mas isso não quer dizer que seja exterior. Para o autor "como seus habitantes foram despidos de todo estatuto político e reduzidos integralmente a vida nua, o campo é também o mais absoluto espaço biopolítico que já existiu, no qual o poder não tem diante de si senão a pura vida biológica sem nenhuma mediação (AGAMBEN, 2015, p. 44). No campo, o homo sacer se confunde com o cidadão.

Se a essência do campo consiste na materialização do estado de exceção e na consequente criação de um espaço em que a vida nua e a norma entram em um limiar de indistinção, deveremos admitir, então que nos encontramos virtualmente na presença de um campo toda vez que é criada tal estrutura, independentemente da natureza dos crimes que aí são cometidos e qualquer que seja a sua denominação ou topografia específica (AGAMBEN, 2010, p. 169-170).

Vida nua é o que a filosofia define o ser puro; na metafísica do Ocidente, as analogias ocorrem no âmbito de sua política, colocando de um lado o homem como animal pensante e, de outro, como animal político. Para

\footnotetext{
${ }^{4}$ Inspirando-se nas considerações de Foucault, Hannah Arendt, Walter Benjamin e Carl Schmitt, Agamben pensa a biopolítica a partir do entrelaçamento de quatro conceitos derivativos da política ocidental: poder soberano, vida nua (homo sacer), estado de exceção e campo de concentração. Foucault faz a descoberta do caráter biopolítico da política moderna, a partir do século XIX, Agamben acredita que ele não se concentra o suficiente nos campos de concentração dos regimes totalitários, melhor analisado por Hannah Arendt, porém, não foi capaz de compreender seu caráter biopolítico. Sem intenção de analisar a justeza dessas críticas, Agamben estabeleceu o nexo entre a dominação totalitária e o caráter biopolítico da política ocidental. A partir da combinação das noções de poder soberano e estado de exceção, Agamben começa a delimitar seu conceito de biopolítica. Soberano, para Carl Schmitt, é aquele que tem poder para decidir e impor o estado de exceção, e é por meio dele que se amplia a brecha para a exposição dos cidadãos ao risco iminente da morte legalmente justificada. Agamben pensa que a dinâmica entre poder soberano e a instituição do estado de exceção não constitui um caso excepcional, mas, sim, a produção do espaço jurídico-político. $\mathrm{O}$ homo sacer como produto da relação entre estado de exceção e poder soberano, tendo em vista que o soberano se encontra dentro e fora do ordenamento legal, detendo o poder de declarar o extado de exceção, situa a figura do homo sacer, o protótipo da vida nua, desprotegida e exposta num contexto de morte sem que se cometa homicídio. O estado de exceção é o instante em que a bíos (bíos politikós), a vida qualificada do cidadão (que merece ser vivida e, portanto, deve ser protegida e incentivada) se converte em ou se torna indiscernível com relação à zoé (a vida nua, desprovida de garantias e exposta à morte) (DUARTE, 2010).
} 
Agamben (2015), são esses conceitos vazios e indeterminados que parecem custodiar firmemente as chaves do destino histórico-político do Ocidente. Aqui é possível visualizar o campo reservado socialmente ao corpo político das mulheres lésbicas. Sua existência perpassa o local permitido pela socialização binária de gênero, pois elas subvertem essa lógica apenas assumindo a sua natural essência em relação àquelas construídas.

Ainda que essa resistência resulte em uma zona de penumbra, na qual o direito não as alcança porque não as reconhece - formando, assim, um estado de exceção, o lugar que a violência contra esse grupo, não se torna permitida, mas não é punida ou garantida por instrumentos jurídicos -, as mulheres lésbicas tornam-se seres políticos nos seus microuniversos de resistência, transformando-se nos seres que vêm, o ser qualquer de Agamben (1993).

O qualquer que o autor propõe não supõe a singularidade na indiferença em relação a uma propriedade comum, mas apenas no seu ser "tal qual é", tomado independentemente de suas propriedades, que identifica sua inclusão em determinado conjunto. Considera-se que ele não remete para uma outra classe ou para a simples ausência genérica de pertença, seja ela qual for, mas para o seu ser-talpara a própria pertença. Assim como o amor não escolhe singularidades, apenas o ser tal qual é (AGAMBEN, 1993).

\section{A MICRORRESISTÊNCIA LÉSBICA NO CONTEXTO HISTÓRICO BRASILEIRO}

Depois de compreendido como as mulheres lésbicas formam identidade mesmo nesse universo de dominação de discursos patriarcais, cabe verificar como se pauta essa violência e quais são as atuais formas de resistências no contexto social brasileiro. Como se sabe, a sexualidade feminina sempre foi muito reprimida, tendo em vista que a sociedade instituiu que o desinteresse por sexo é uma característica da mulher respeitável, recatada.

Como a sociedade constrói as leis, surge então a dificuldade em elaborar documentos que abordem e aceitem a temática da homossexualidade feminina, o aborto, a anticoncepção, entre outros temas tabus, mesmo que façam parte da realidade. A violência de gênero é um fenômeno amplamente discutido e documentado, sendo que as legislações e políticas se renovam a cada ano buscando reparar os males que a dominação patriarcal provocou e continua causando. Embora se observe um retrocesso em disparidades de gênero, ainda assim mulheres e homens não têm os mesmos direitos ou liberdade; vive-se em escalas diferentes seja na esfera pública ou privada, assim a realidade da mulher ainda é permeada por medo e desigualdade.

A violência contra lésbicas é específica, tem cunho de repressão, une sexismo, misoginia, preconceito contra a orientação sexual e opressão de gênero. Uma lésbica, antes de mais nada, é uma mulher, que convive diariamente com o machismo. Quando se assume lésbica e abdica de se relacionar com homens, o preconceito contra sua orientação aparece em forma de assédio, de apagamento e de violência. A necessidade de uma palavra que defina o tipo de violência emerge exatamente dessas circunstâncias da opressão de gênero + preconceito: a 
lesbofobia é o casamento da homofobia com a misoginia e o sexismo.

Os homossexuaismasculinos são discriminados, mas são visíveis. $\mathrm{Na}$ visibilidade, a luta e o enfrentamento são constantes, e a orientação sexual é nítida, não ocultada. As lésbicas, que já seriam discriminadas naturalmente por conta da sua condição de gênero, sofrem preconceito triplicado por não corresponderem à sua "determinação comportamental socialmente estabelecida" e ainda por tentarem "disputar" o espaço historicamente reservado aos homens. Uma mulher lésbica é sempre subjugada pela sua subversão.

As consequências práticas dessa visão distorcida e segmentária da sociedade em relação às lésbicas não são, infelizmente, difíceis de se observar. Não há acessibilidade da mulher lésbica aos órgãos policiais e jurídicos justamente por se desconhecer o tipo específico de violência que elas sofrem e pela falta de dispositivos jurídicos de proteção. Ainda que haja uma extensa legislação de proteção à mulher, o atendimento precário e o machismo circunscrito em todas as searas sociais impedem o pleno acesso. A situação é ainda mais complexa quando se analisa o acesso lésbico ao sistema público de saúde.

Para Mérli Leal Silva (2013) e Larissa Alves de Freitas Marques (2012), não são poucas as mortes causadas pelo desconhecimento dos profissionais da saúde em lidar com a homossexualidade feminina. Eles simplesmente conjeturam a heterossexualidade da paciente, confirmando muitas vezes seu desconforto diante de asserções em sentido contrário. Muitas lésbicas são mal norteadas pelos profissionais ou facilmente deixam de frequentar os consultórios por conta de constrangimentos sofridos durante as consultas. (SILVA, 2013).

Para Marques (2012), a heteronormatividade - influente nos currículos dos cursos da área de saúde e, por conseguinte, nos centros de tratamento - limita a atuação dos profissionais, que sequer conhecem as especificidades do sexo entre mulheres. Com frequência, as mulheres lésbicas são levadas a acreditar serem imunes de doenças sexualmente transmissíveis, já que não há campanhas de educação ou políticas de aconselhamento que reforcem o contrário.

Os preconceitos dos profissionais da saúde também são a causa de as pacientes abandonarem tratamentos ou consultas ginecológicas, que deveriam ser regulares. Segundo Silva (2013), o problema da segregação e da invisibilidade social das lésbicas no sistema de saúde contrasta com a visibilidade dos homossexuais masculinos, muito mais expostos e, por isso, mais bem reconhecidos pelo sistema de saúde pública, sobretudo no que se refere à aids.

As lésbicas lembradas e reconhecidas como "antinaturais", pois não estão à disposição dos homens e se recusam à posição de submissão a eles, foram marcadas pelo estigma de não serem "mulheres reais" e, ao mesmo tempo, por "querer ser homens", como restou comprovado na seção anterior. Para Wittig (1992), recusar-se a ser mulher não significa querer tornar-se homem. Cita o exemplo da Butch, a mulher vista socialmente como "masculina", no Brasil, chamada de "fancha, sapatão, caminhoneira, paraíba, etc.", que causa horror e provoca uma 
certa aversão social, mas, mesmo assim, ao querer tornar-se homem, está "escapando da programação inicial" (WITTIG, 1992, p. 12).

A produção das mulheres no quadro de pertencimento à categoria dos homens lembra que as lésbicas não podem ser mulheres nos termos assim impostos pela sua programação inicial. Também não podem tornar-se um homem, já que isso estabeleceria a consciência de que eles dispõem das mulheres como suas. A opressão lésbica incide em que as mulheres estão fora do alcance dos homens, não pertencem a eles de maneira alguma; logo, não podem ser qualquer outra coisa, como um produto da sociedade, não um produto da natureza como as mulheres, por isso tantas vezes são acusadas de antinaturais, aberrações, desvios (LESSA, 2007).

Atualmente, os direitos sexuais e reprodutivosdas mulheres ganham força e são discutidos cada vez mais; porém, à medida que bocas revolucionárias se abrem para debatê-los, verificam-se forças conservadoras e baseadas na religião que se unem para calá-las. Para maior entendimento, faz-se necessária uma breve evolução histórica a respeito do surgimento da expressão direitos reprodutivos: sua raiz está na luta das mulheres, quando elas entraram em marcha para garantir a autodeterminação sexual, a capacidade de decidir quando e como querem ter filhos e o controle do seu próprio corpo.

Os direitos reprodutivos vieram a público no I Encontro Internacional de Saúde da Mulher realizado em Amsterdã, na Holanda, em 1984. Houve uma concordância plena de que essa qualificação traduzia um conceito mais completo e adequado do que é saúde da mulher para a ampla pauta de autodeterminação reprodutiva das mulheres. A formulação do conteúdo dos direitos reprodutivos iniciou em um marco não institucional, a partir da desconstrução da maternidade como um dever, por meio da luta pelo direito ao aborto e à anticoncepção em países desenvolvidos (MATTAR, 2008).

No final dos anos 1970 e início da década de 1980, iniciaram-se movimentos em diversos países para que as mulheres pudessem determinar a sua vida reprodutiva e sexual com segurança e saúde, visando bem-estar social e econômico, sem que a sua conduta de liberdade afetasse o modo de ser vista pela sociedade. A busca de significado aos direitos sexuais e reprodutivos foi expandida até que englobasse as necessidades sociais que impediam o controle feminino do corpo e da reprodução sexual.

É aí que se apresenta a resistência lésbica, ao lado do movimento feminista, embora muitas vezes também invisibilizada por ele. Mesmo com todas as amarras sociais levando à rede de dominação patriarcal e à heteronormatividade, o amor entre mulheres surge e renasce, arraigando-se, subvertendo e produzindo novos saberes e campos a serem investigados. Assim, cabe ir mais além e analisar como, de fato, essa resistência organizou-se em território nacional.

Como asseveram Almeida e Heilborn (2008, p. 229), no lesbianismo político brasileiro da contemporaneidade diferentes sujeitos vocalizam suas propostas, suas demandas e divergências por meio ou da 
militância partidária, ou de grupos com baixo grau de formalidade, ou, ainda, por meio de organizações não governamentais. Recentemente, estes sujeitos também se articularam

em torno de grandes entidades agregadoras nacionais, como a LBL (Liga Brasileira de Lésbicas), ABGLT (Associação Brasileira de Gays, Lésbicas e Transgêneros) e a ABL (Articulação Brasileira de Lésbicas). Estas entidades, por sua vez, divergem por diferentes motivos: desde disputas de poder e de espaço de representação governamental entre lideranças, até desavenças quanto à demarcação de fronteiras identitárias. Há posições entre as francamente favoráveis à articulação com os gays, bissexuais e travestis - pela potencialização da ação política -, e as que consideram prejudicial ao reconhecimento público das demandas especificamente lésbicas tal articulação. Atualmente as ONGs compõem a fração de maior força social no movimento de lésbicas. Este movimento, como outros, envolve um fazer - por meio de um conjunto de procedimentos - e um pensar - por meio de um conjunto de ideias que motiva ou dá fundamento à ação. Trata-se de uma práxis, portanto, movimento lésbico, embora tomado em sua conformação atual, possui uma história com caráter cíclico, que se manifesta em processos de fluxo e refluxo não referidos a relações de causalidade mecânica, mas à dinâmica social, em sua totalidade.

O Dia Nacional da Visibilidade Lésbica é comemorado em 29 de agosto. A data foi criada por ativistas lésbicas brasileiras em 1996, durante o 10 Seminário Nacional de Lésbicas (Senale), como um marco na luta de mulheres brasileiras que têm seus direitos violados diariamente por sua orientação sexual. Esse Movimento busca visibilizar a existência lésbica, bem como reivindicar demandas, diante da violência, mas também intenta uma transformação social como um todo. Cabe trazer alguns dados estatísticos que demonstrem a dimensão do problema: de acordo com o balanço divulgado pela Ouvidoria Nacional dos Direitos Humanos, dos mais de 130 mil casos de violações de direitos humanos denunciados em 2015, 23\% das vítimas eram gays; $12 \%$, travestis; 10\%, lésbicas; $9 \%$, transexuais e $2 \%$ eram bissexuais ${ }^{5}$.

\section{CONCLUSÃO}

As narrativas socialmente reproduzidas domesticam as percepções sobre amor, romance e desejo, daí a deslegitimação das identidades e das relações homossexuais. As mulheres lésbicas são caracterizadas como seres místicos, não reconhecidos, ou apenas como corpos confusos, imersos em um contexto social de subversão, que atua como ameaça à norma padrão de gênero e sexualidade. Logo, o que se entende como "normal" são os discursos historicamente reproduzidos pautados na heterossexualidade e no sistema binário de gênero.

O necessário para reconhecimento dos corpos invisibilizados nessa padronização social é o entendimento de como se produziu esse biopoder, bem como uma análise acerca da produção de identidade conquistada pela resistência de corpos políticos. A partir da reconstrução e do reconhecimento da identidade lésbica individual e coletiva, pode ser possível, também, conhecer as lutas sociais e as ações afirmativas buscadas para que os direitos não conquistados sejam alvitrados, a fim de legitimar a condição de corpo visível e 
resguardado dessas mulheres. Além disso, podem ser verificadas medidas que transformem os discursos sociais dominantes e erradiquem os preconceitos e os estigmas demonstrados no decorrer desta pesquisa.

A polarização das categorias de gênero acentua uma supremacia masculina histórica, científica e culturalmente legitimada, contribuindo para a submissão das mulheres e, por consequência, para uma organização social em que os direitos são díspares. As revoluções sexuais muito influenciadas pelo movimento feminista cooperam para uma libertação feminina e para a transformação social que impulsiona a garantia de direitos, outrora negados, às mulheres. Contudo, essa situação está longe de ser considerada ideal, visto que o sistema patriarcal ainda atua fortemente na regulação da vida. Engendrada com o patriarcado, situa-se a heteronormatividade, ou seja, um sistema que regula as relações afetivas e sexuais de forma binária e dualista: a heterossexualidade é entendida como natural e desejável, ao passo que a homossexualidade é vista como anormal e imprópria.

As mulheres, em sua maioria, uniram-se e resistiram às amarras sociais e, embora a luta persista e seja diária, são perceptíveis as várias transformações sociais que resultaram das reivindicações dos movimentos sociais no geral. As mulheres lésbicas, por sua vez, inseridas nesses movimentos, reclamaram seus espaços, mas, ainda assim, carecem de um olhar social, cultural, científico e jurídico voltado para sua condição específica no meio social; principalmente, sugere-se um olhar a partir de políticas públicas de promoção de saúde, de educação e de proteção à lesbofobia diária sofrida por esse grupo. Assim, é com a pretensão de analisar os caminhos para a efetivação de direitos e visibilidade dos corpos políticos das lésbicas que esta pesquisa foi conduzida.

\title{
BETWEEN IDENTITIES AND (MICRO)RESISTANCE: WHERE ARE THE LESBIANS?
}

\begin{abstract}
The relation of the body exceeds the domain of the particular, since the subjects are inserted in a sociocultural contexts, transiting towards the public, and have their individuations from the contact with the others. That way, for the visibility of lesbian existence, there is a need to overcome, firstly, patterns imputed by the patriarchal system, and, secondly, a social erasure suffered by lesbian women in the course of history. This research is justified by the need to break stereotypes and stigmas that permeate lesbian identity, by (re) knowing the difference in the academic environment, it is also possible a cultural and social change, beyond the invisibility of these women. The research method to be used will be hypothetico-deductive. The research technique will be the bibliographical research, with consultations in books, scientific articles, journals, legislation and other pertinent documents.
\end{abstract}

Keywords: Lesbians; Identity; Micro Resistance; Human Rights.

\footnotetext{
${ }^{5}$ ANDES UFSC (Santa Catarina). 29 de agosto: Dia Nacional da Visibilidade Lésbica. 2016. Disponível em: <http://andesufsc.org.br/29-de-agosto-dia-nacional-da-visibilidade-lesbica/>. Acesso em: 29 dez. 2016.
} 


\section{REFERENCIAS}

AGAMBEN, Giorgio. Meios sem fim: notas sobre a política. Belo Horizonte: Autêntica, 2015.

Homo Sacer: o poder soberano e a vida nua. 2. ed. Belo Horizonte: UFMG, 2010.

A Comunidade que vem. Lisboa: Presença, 1993.

ALMEIDA, Gláucia; HEILBORN, Maria Luiza. Não somos mulheres gays: identidade lésbica na visão de ativistas brasileiras. Revista Gênero, v. 9, n. 1, 2008.

BAUMAN, Zygmunt. Identidade: entrevista a Benedetto Vecchi. Tradução: Carlos Alberto Medeiros. Rio de Janeiro: Jorge Zahar, 2005.

BEAUVOIR, Simone de. O segundo sexo. 2. ed. Tradução Sérgio Milliet. Rio de Janeiro: Nova Fronteira, 2009.

DUARTE, André. Vidas em risco: crítica do presente em Heidegger, Arendt e Foucault. Rio de Janeiro: Forense Universitária, 2010.

FALQUET, Jules. Romper o tabu da heterossexualidade: contribuições da lesbianidade como movimento social e teoria política. Cadernos de Crítica Feminista, Ano VI, N. 5, p. 1-24, 2012.

FIRESTONE, Shulamith. A dialética do sexo: um manifesto da revolução feminista. Editorial Labor do Brasil, 1976.

FOUCAULT, Michel. História da Sexualidade I: a vontade de saber. Rio de Janeiro: Graal, 1988.

Microfísica do poder. Rio de Janeiro: Graal, 1979.

GIDDENS, Anthony. As consequências da modernidade. São Paulo: Unesp, 1990.

HALL, Stuart. A Identidade Cultural da pós-modernidade. 6. ed.. Rio de Janeiro: DP\&A, 2001.

HERMES, Ana Luiza Fay. Para além do claustro, um pensamento da diferença: Jacques Derrida e a desconstrução da metafísica da presença. Sapere Aude Revista de Filosofia, v. 4, n. 7, p. 224-244, 2013.

LESSA, Patrícia. O feminismo-lesbiano em Monique Wittig. Revista Ártemis, n. 7, p. 93-100, 2007.

MARQUES, Larissa Alves de Freitas (org). A Lesbofobia no sistema de saúde brasileiro. Práticas e implicações da discriminação institucional nesta esfera, e o papel do Serviço Social na garantia de direitos das lésbicas. Anais do Congresso Internacional de Estudos sobre a Diversidade Sexual e de Gênero - ABEH. V. 1, N. 1. Salvador: UFBA, 2012.

MATTAR, Laura Davis. Reconhecimento jurídico dos direitos sexuais: uma análise comparativa com os direitos reprodutivos. SUR Revista Internacional de Direitos Humanos, v. 5, n. 8, p. 60-83, 2008.

MILLET, Kate. Política Sexual. Lisboa: Dom Quixote, 1970.

NAVARRO-SWAIN, Tania. Feminismo e lesbianismo: a identidade em questão. Cadernos Pagu, n. 12, p. 109$120,2015$.

Lesbianismo: identidade ou opção eventual? In:Fronteiras de Gênero, Anais do XX Simpósio Nacional de História - ANPUH, p. 1223 - 1239. Florianópolis, julho 1999. 
SILVA, Mérli Leal. Imagens em Comunicação e Saúde: Lésbicas e Bissexuais no Sistema Único de Saúde no Brasil - Olhares Freireanos. Encontro Nacional de História e Mídias Alternativas. UFRGS Online. Disponível em: http://www.ufrgs.br/alcar/encontros-nacionais-1/9o-encontro-2013/artigos/gt-historia-da-midiaalternativa/imagens-em-comunicacao-e-saude-lesbicas-e-bissexuais-no-sistema-unico-de-saude-no-brasilolhares-freireanos Acesso em: 13 out. 2016.

WITTIG, Monique. The straight mind and other essays. Beacon Press, 1992.

Trabalho enviado em 28 de agosto de 2017. Aceito em 12 de dezembro de 2017. 